\title{
Observed climate variability and change in Urmia Lake Basin, Iran
}

\author{
A. H. Delju • A. Ceylan • E. Piguet • M. Rebetez
}

Received: 15 September 2011 / Accepted: 3 April 2012 /Published online: 8 May 2012

(C) Springer-Verlag 2012

\begin{abstract}
This paper analyzes climate variability and change in the Urmia Lake Basin, northwest of Iran. Annual average of the following data time series has been analyzed by statistical methods: dry bulb temperature, maximum and minimum temperature, precipitation, and number of rainy and snowy days. We have also used mean monthly temperature and precipitation data for analysis of drought spells for the period 1964-2005 to find out whether fluctuations in the lake level are attributable to natural drought. Our results indicate that mean precipitation has decreased by $9.2 \%$ and the average maximum temperature has increased by $0.8^{\circ} \mathrm{C}$ over these four decades. The seasonal changes are particularly visible in winter and spring. Results of the Palmer Drought Severity Index show that on average, drought episodes have hit the Urmia Lake Basin every 5 years and most of them reached severe levels, but recent droughts have become more intense and last longer.
\end{abstract}

\section{Introduction}

Iran with approximately $1,600,000 \mathrm{~km}^{2}$ is a vast country where its climate is mainly controlled by the wide latitudinal extent (from $25^{\circ} \mathrm{N}$ to $40^{\circ} \mathrm{N}$ ) and by the pronounced

A. H. Delju $(\bowtie) \cdot$ E. Piguet

IGG Geography Institute, University of Neuchâtel,

Neuchâtel, Switzerland

e-mail: amir.delju@unine.ch

A. Ceylan

Turkish State Meteorological Service (TSMS),

06120 Kalaba, Ankara, Turkey

M. Rebetez

WSL Swiss Federal Research Institute,

CP 96, 1015 Lausanne, Switzerland topography. Most of Iran, due to its low annual precipitation (about $250 \mathrm{~mm}$ ), is classified as either arid or semiarid according to various climate classifications (Ghasemi and Khalili 2007). Beyond these geographical factors which affect the climate, sometimes the precipitation and temperature variability are to a great extent linked to larger global systems. However, localized studies reveal more specified details that provide better insight of the situation.

The precipitation varies over the country. There are some regions in the south of the Caspian Sea or in the Zagross Mountains that receive up to $2,000 \mathrm{~mm}$ of annual precipitation, whereas a portion of southern and eastern part of Iran gets less than $50 \mathrm{~mm}$. Furthermore, most of the precipitation in Iran falls during the winter and autumn seasons due to the prevalence of humid westerly winds of Mediterranean origin. Differently, there are regions in the northwestern part of the country that have the largest share of precipitation during spring (Domrös et al. 1998; Dinpashoh et al. 2004).

Similar to other regions of Iran, northwest of the country has experienced frequent dry periods in recent decade. Although rapid decrease in the level of the Urmia Lake has been mostly observed during dry periods, we have tried to monitor the lake level fluctuations and naturally imposed dry/wet episodes to understand merely the role of natural impacts on the lake. We did not factor in external forcing and human intervention such as changes in water consumption patterns and water flow to the lake. Since early 2000 , the Urmia Lake has lost more than $6 \mathrm{~m}$ of its depth out of $16 \mathrm{~m}$, mainly due to dry climate and change of water consumption patterns for irrigated agricultural operations. We have noted that climate studies for this area are poorly documented. As a result, this is the first paper which reviews local trends of temperature, precipitation, and meteorological drought in the selected area based on observed parameters at the Urmia synoptic station for a period of 1964-2005. 
The station has been selected because it represents the longest period of consistent observation with reliable data in the Urmia Lake Basin. The objective of the paper is to understand the trends in temperature, precipitation, and drought cycles in the water stressed study area and attribute the dry/wet periods on fluctuations of the lake level.

The next parts of the paper are organized as follows: In Section 2, the study area and the data used for the analysis including a description of the methodology are presented. Section 3 provides the main results of the study, and Section 5 discusses the implications and various aspects of the result. The last section is dedicated to conclusion.

\section{Study area, data, and methods}

\subsection{The study area}

The study area is located between $37^{\circ} 4^{\prime}$ to $38^{\circ} 17^{\prime}$ latitude and $45^{\circ} 13^{\prime}$ to $46^{\circ}$ longitude. The Urmia Lake is the 20th largest lake and the second hypersaline lake (before September 2010) in the world. The lake is also the largest inland body of salt water in the Middle East with an area that varied from 2,000 to $2,300 \mathrm{mi}^{2}\left(5,200\right.$ to $\left.6,000 \mathrm{~km}^{2}\right)$ in the twentieth century. It is about $87 \mathrm{mi}(140 \mathrm{~km})$ long and $25-35 \mathrm{mi}$ $(40-55 \mathrm{~km})$ wide, with a maximum depth of $53 \mathrm{ft}(16 \mathrm{~m})$ which classifies it a shallow lake, making it more vulnerable to evaporation, (Sorgeloos 1987). About 20 permanent and seasonal rivers as well as few submarine streams and springs feed the lake (Rasuly 2005).

Urmia Lake is a shallow and saline lake, located in the northwestern part of Iran surrounded by East and West Azerbaijan provinces, near the Turkish border. More than seven million people are living in two neighboring provinces around the lake, and agriculture, horticulture, animal husbandry, handicraft making, apiculture, mining, business, and industry play a major role in the region. In the coastal zone, recreational activities, tourism, artemia harvesting, salt extraction, and hunting are common sources of income. Climate in the Urmia Lake Basin is harsh and continental, affected mainly by the mountains surrounding the lake (Ghaheri and Baghal-Vayjooee 1999). Considerable seasonal fluctuations in air temperature occur in this semiarid region. The annual average precipitation is $341 \mathrm{~mm}$ (Islamic Republic of Iran Meteorological Organization (IRIMO), http://irimo.ir/english/monthly\&annual/r25.asp). The minimum and maximum temperature in the region ranges between 0 and $-23^{\circ} \mathrm{C}$ in winter and up to $39^{\circ} \mathrm{C}$ in summer (IRIMO, http://www.irimo.ir/english/monthly\&annual/ r6.asp). From this point of view, Urmia Lake is a critical asset for the region because it contributes to moderating the temperature extremes and makes the climate favorable for fungi and fauna (Street-Perrott et al. 1983).
On the other hand, circulation of sea breeze, penetrating inland and local heights, has a marked effect on local climate and generates low level local clouds. The lake has been designated as a national park and as a site within Ramsar Convention on Wetlands (Eimanifar et al. 2007).

Figure 1 shows the Urmia Lake. The normal total catchment area of the lake was about $51,876 \mathrm{~km}^{2}$ which composed $3.15 \%$ of the entire country and included $7 \%$ of the total surface water in Iran (Urmia Lake Basin Integrated Water Resources Management Home Page (IWRM), http:// www.wri.ac.ir/urmia/English/index.html).

Historically, the volume of water in the lake was estimated to be $19,000,000,000 \mathrm{~m}^{3}$, with an area of about $5,700 \mathrm{~km}^{2}$. The area of the Urmia Lake in 1998 and 2001, respectively, equaled to 5,650 and 4,610 $\mathrm{km}^{2}$ (Azizi 2000). The area of the lake decreased approximately $1,040 \mathrm{~km}^{2}$ during that period; however, since then it has been shrinking at a much faster pace.

In view of the dependence of agricultural operations on runoff and ground water resources, 35 dams have been built on 21 rivers flowing to the lake. As a result, the combined effect of these dams along with high exploitation of ground water intensified by recent drought cycles has brought the lake to a critical situation. Figure 2 illustrates withdraw of shorelines based on monitoring of LANDSAT- 5 images (PECAD n.d.). Furthermore, the lake height variations, monitored by TOPEX/POSEIDON/Jason-1 and Jason-2/OSTM Altimetry satellites, are presented in Fig. 3 (PECAD n.d., http:// www.pecad.fas.usda.gov/cropexplorer/global_reservoir/).

The lake level variation equaled to $3 \mathrm{~m}$ from August 1998 to August 2001, approximately; however, the receding level has gained more rapid pace since early 2010 . The level of variation equaled to $6.8 \mathrm{~m}$ from January 1992 to August 2010. As a result, this has rapidly changed shorelines and caused a disappearance of the existing landscape in the region. Persistence of this phenomenon plus other subsidiary impacts of climate change such as rapid reduction in ground water resources, loss of land productivity, degradation of agricultural lands, soil erosion, and salinization associated with water scarcity seem to be strong enough to trigger a possible future migration and human displacement of a vulnerable rural population from dry lands to other areas in the country.

\subsection{Data}

In this study, the annual average of the following parameters observed in Urmia synoptic station was made available by IRIMO: dry bulb temperature, maximum and minimum temperature, annual precipitation data, and monthly number of rainy and snowy days. We have also analyzed drought spells for the period 1964-2005 in the Urmia Lake Basin, using mean monthly temperature and precipitation data for 


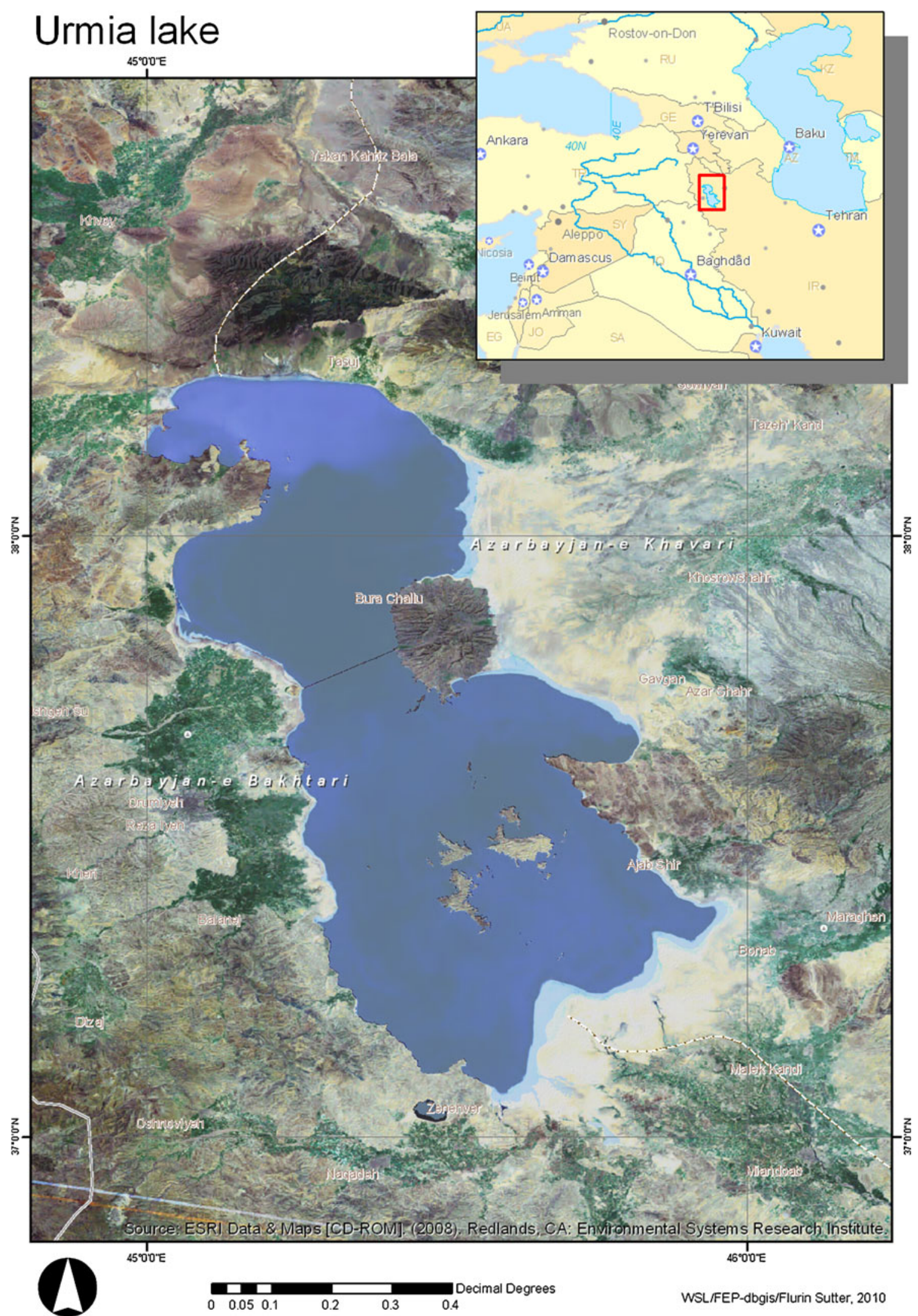

Fig. 1 Geographic location of the Urmia Lake and the study area, northwest of Iran. Courtesy of Flurin Sutter, WSL, Switzerland 


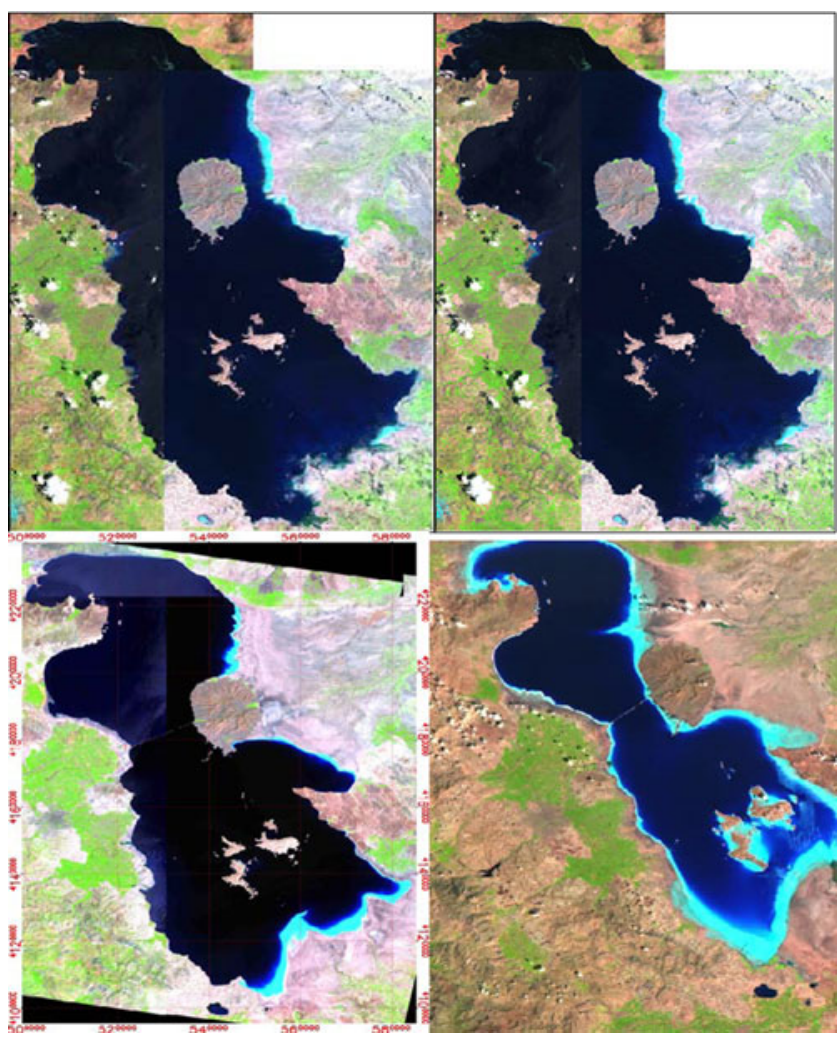

Fig. 2 Urmia Lake in June 1989 (top left), August 1998 (top right), August 2001 (bottom left), August 2010 (bottom right). Courtesy of USDA/FAS/ OGA and NASA Global Agriculture Monitoring (GLAM) Project

the same period. The station identifiers and geographical data, as defined in Aguilar et al. (2003) and World Meteorological Organization (2003), are given in Table 1.

The metadata records for Urmia synoptic station, made available by IRIMO, showed that since the implementation
Table 1 Urmia synoptic station identifiers and geographical data

\begin{tabular}{ll}
\hline Station name & Urmia synoptic station \\
\hline WMO no. & 40712 \\
Longitude & $\mathrm{E} 45^{\circ} 03^{\prime} 00^{\prime \prime}$ \\
Latitude & $\mathrm{N} 37^{\circ} 40^{\prime} 00^{\prime \prime}$ \\
Elevation (MSL) & $1,328 \mathrm{~m}$ \\
Opening date & 2 October 1956 \\
Relocations (1) & 23 July 1973 (moved $15 \mathrm{~km})$ \\
Relocations (2) & 6 May 2004 (moved $500 \mathrm{~m}$ ) \\
Topographic status & Mountainous \\
Natural vegetation & Steppe \\
\hline
\end{tabular}

of the Urmia synoptic station in 1956, there has not been interruption in its operation. In the case of two relocations of the station, the distance has been shorter than $30 \mathrm{~km}$. Furthermore, the local environment from the first place to the relocated area has not changed as well. As a result, this has eliminated the impact of non-climatic factors in data homogenization. The randomness of the annual data sets (1964 2005) of mean temperature, precipitation, as well as the number of rainy/snowy days was investigated through tests for homogeneity, absence of artificial trends, and spurious autocorrelation.

\subsection{Methods}

\subsubsection{Kruskal-Wallis}

The annual average temperature and annual total precipitation data of Urmia synoptic station were tested by using
Fig. 3 Urmia Lake height variations. Courtesy of the USDA/FAS/OGA and NASA Global Agriculture Monitoring (GLAM) Project

\section{Lake Urmia Height Variations}

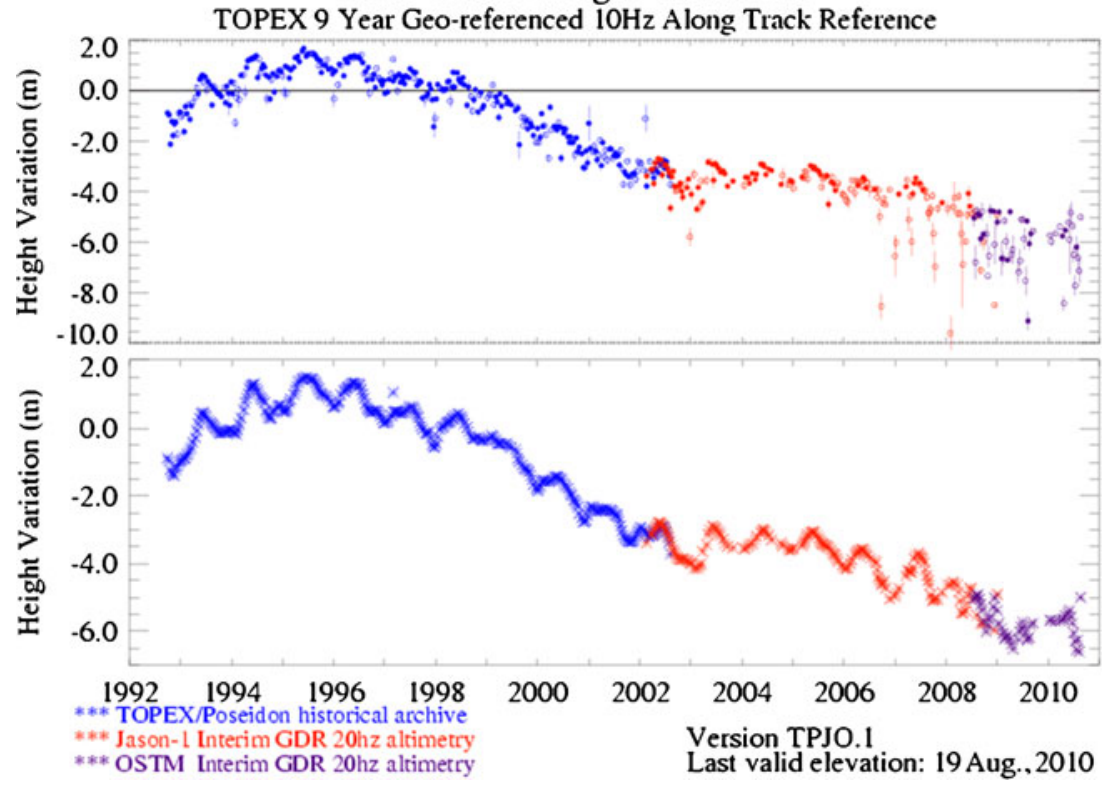


Kruskal-Wallis $(\mathrm{K}-\mathrm{W})$ method. For annual data, there was no number of homogeneous or inhomogeneous records (see Sneyers 1990, WMO TD no. 143). This being the case, in order to verify the homogeneity of the series, we limited ourselves to verifying the homogeneity of the empirical means while ensuring the compatibility of their empirical variance with the empirical variance of the sample sizes of the original series. $\mathrm{K}-\mathrm{W}$ statistical test value of dry bulb temperatures was obtained as $X=$ 18.7. For the four degrees of freedom, the value is $\chi^{2}=$ 9.49. According to this result, the data of dry bulb temperature are inhomogeneous. But this is just because of the presence of the statistically meaningful decreasing trend $(z=-1.94)$ of this variance. $\mathrm{K}-\mathrm{W}$ statistical test value of annual total precipitation was obtained as $X=$ 9.43. For the three degrees of freedom, the value is $\chi^{2}=$ 7.81. According to this result, the data of annual total precipitation is inhomogeneous. But this is just because of the presence of the statistically meaningful decreasing trend $(z=-2.517)$ of this variance. The obtained confidence level is $\alpha=0.95$.

\subsubsection{The Mann-Kendall rank correlation test}

The Mann-Kendall rank correlation test (Sneyers 1990) was chosen to detect any possible trend in the means of precipitation and temperature time series of annual and seasonal precipitation totals recorded at the Urmia station, respectively, during the period 1964-2005. Using the ordered numbers for all $y i$ value $i>j$, we can find a number $n i$ denoting the number of $y i-1$ elements which can be found by calculating the number of sequences $y i>y i-1$. Test statistics value.

$t=\sum_{i=1}^{n} n_{i}$

\subsubsection{Palmer Drought Severity Index}

The Palmer Drought Severity Index (PDSI) for the Urmia station has been calculated based on observed mean monthly precipitation and temperature records for the period 1964-2005. The PDSI is a measurement of dryness based on recent precipitation and temperature. The PDSI
Table 3 Drought classification by PDSI value

\begin{tabular}{ll}
\hline 4.00 or more & Extremely wet \\
3.00 to 3.99 & Very wet \\
2.00 to 2.99 & Moderately wet \\
1.00 to 1.99 & Slightly wet \\
0.50 to 0.99 & Incipient wet spell \\
0.49 to -0.49 & Near normal \\
-0.50 to -0.99 & Incipient dry spell \\
-1.00 to -1.99 & Mild drought \\
-2.00 to -2.99 & Moderate drought \\
-3.00 to -3.99 & Severe drought \\
-4.00 or less & Extreme drought \\
\hline
\end{tabular}

is based upon a set of empirical relationships derived by Palmer (1965) to express regional moisture supply standardized in relation to local climatological norms. The index is a sum of the current moisture anomaly and a fraction of the previous index value. The moisture anomaly is defined as

$d=P-P$

where $P$ is the total monthly precipitation and ${ }^{\wedge} P$ is the precipitation value "climatologically appropriate for existing conditions" (Palmer 1965). The index has proven most effective in determining long-term drought (Alley 1984). The critical $(z)$ values of significance level $(\alpha)$ and PDSI classification values are given in Tables 2 and 3 , respectively.

\subsubsection{The Emberger classification}

In 1930, Emberger elaborated a synthetic expression for the Mediterranean climate (Daget 1977), classifying this kind of climate based on three important climatic parameters: precipitation, temperature, and evaporation. The precipitation $(P)$ is represented by the annual precipitation (millimeters). For temperature, the mean of the maximum temperatures of the hottest month in the year $(M)$ and the mean of the minimum temperatures of the coldest month $(m)$ in the year were considered because vegetation growth is strictly related to these thermal limits.

Table 2 Critical $z$ values in some significance level for one and two-sided tests

\begin{tabular}{|c|c|c|c|c|c|}
\hline Significance level $(\alpha)$ & 0.10 & 0.05 & 0.01 & 0.005 & 0.002 \\
\hline Critical $z$ values for one-sided test & -1.28 or +1.28 & -1.645 or +1.645 & -2.33 or +2.33 & -2.58 or +2.58 & -2.88 or +2.88 \\
\hline Critical $z$ values for two-sided test & -1.645 and +1.645 & -1.96 and +1.96 & -2.58 and +2.58 & -2.81 and +2.81 & -3.08 and +3.08 \\
\hline
\end{tabular}


Fig. 4 Palmer Drought

Severity Index for Urmia station, Iran (1964-2005)

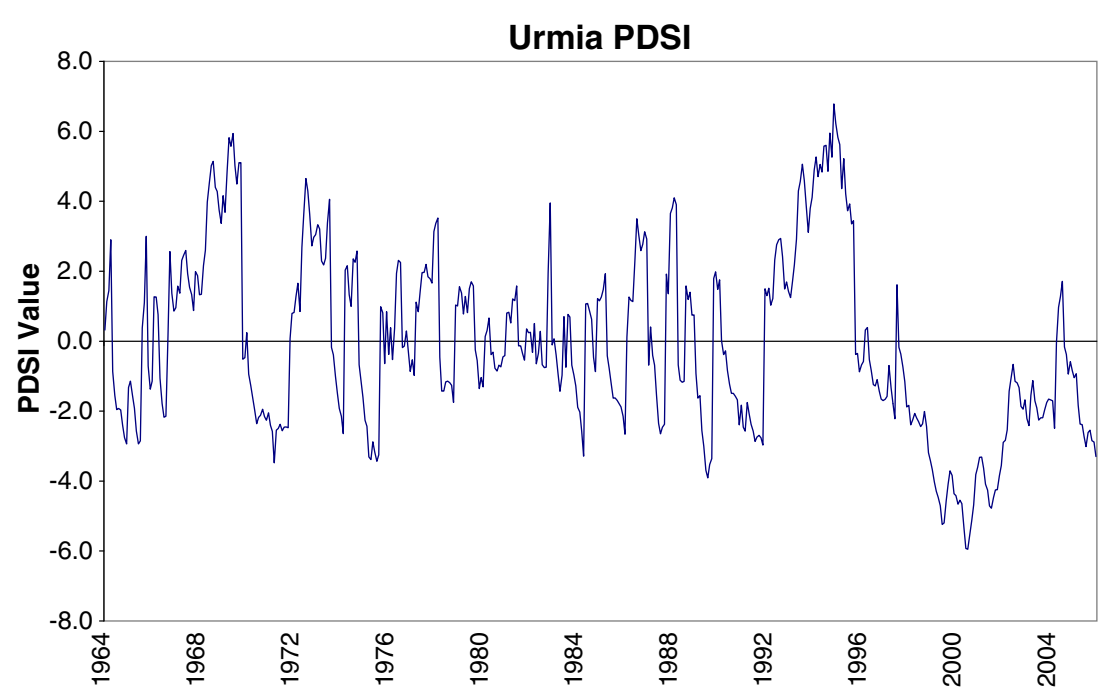

The temperature parameter is represented by the quotient $(M / 2+m / 2)$. Evaporation is represented by the temperature range $(M-m)$ because evaporation frequently increases with it. This parameter indicates a continental climate (Calvet 1964).

\subsubsection{The Thornthwaite's method (water balance)}

In order to explore the water balance in the Urmia station, Thornthwaite's method has been used to illustrate the water budget as a methodology for estimating
Fig. 5 Seasonal variations of daily mean temperature (left) and precipitation (right) Urmia station, Iran (1964-2005)
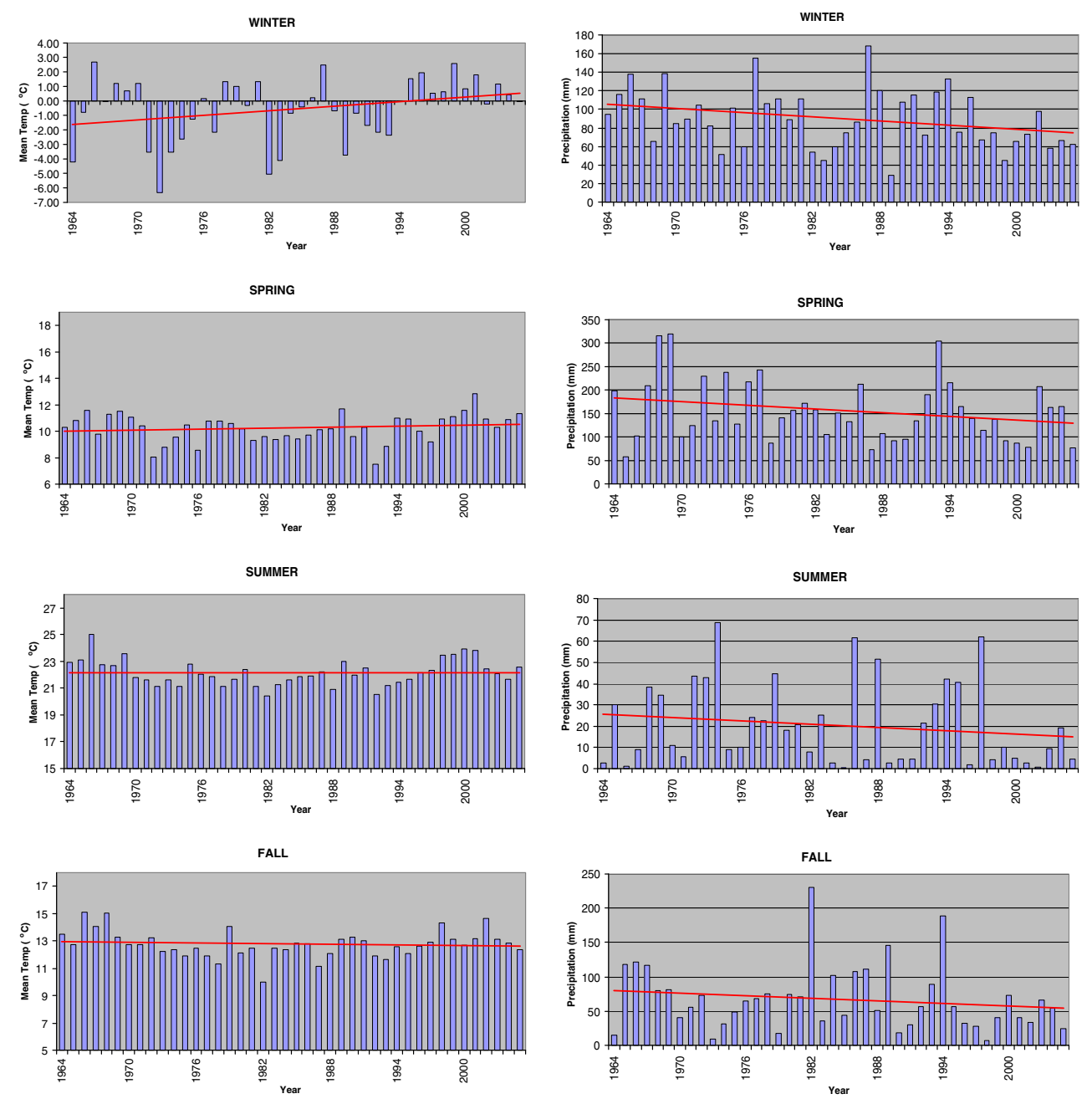
water surpluses and runoff and the difference between them. The method is based on an annual temperature efficiency index $(J)$, defined as the sum of 12 monthly values of heat index $(I)$. Each index $(I)$ is a function of the mean monthly temperature $T$ in degrees Celsius as follows:

$I_{i}=\left(T_{i} / 5\right)^{1.514}$
Evaporation was calculated by the following formula:

$(I=\Sigma i) ; i=1 \ldots 12$

$a=675 \times 10^{-9} \times \mathrm{I}^{3}-711 \times 10^{-7} \times \mathrm{I}^{2}+1,792$

$\times 10^{-5} \times I+492.4 \times 10^{-3}$ and ETP $=1.6(10 t / I)^{a}$

Urmia

Trend Analysis of PDSI Result
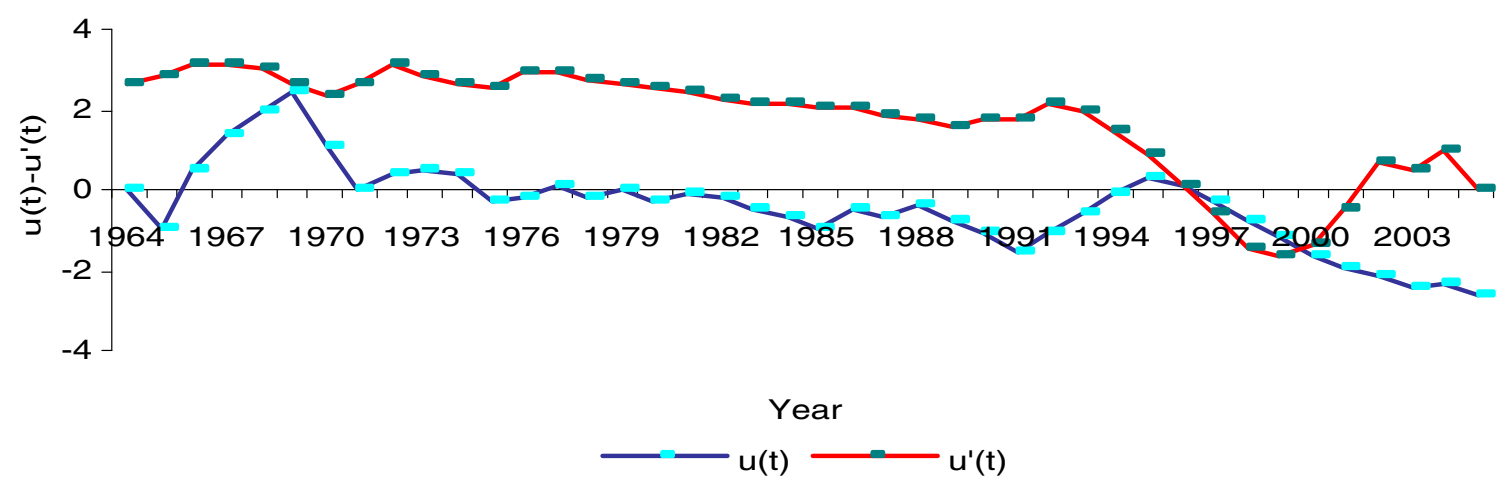

Urmia

Annual Mean Temperature Trend Analyses

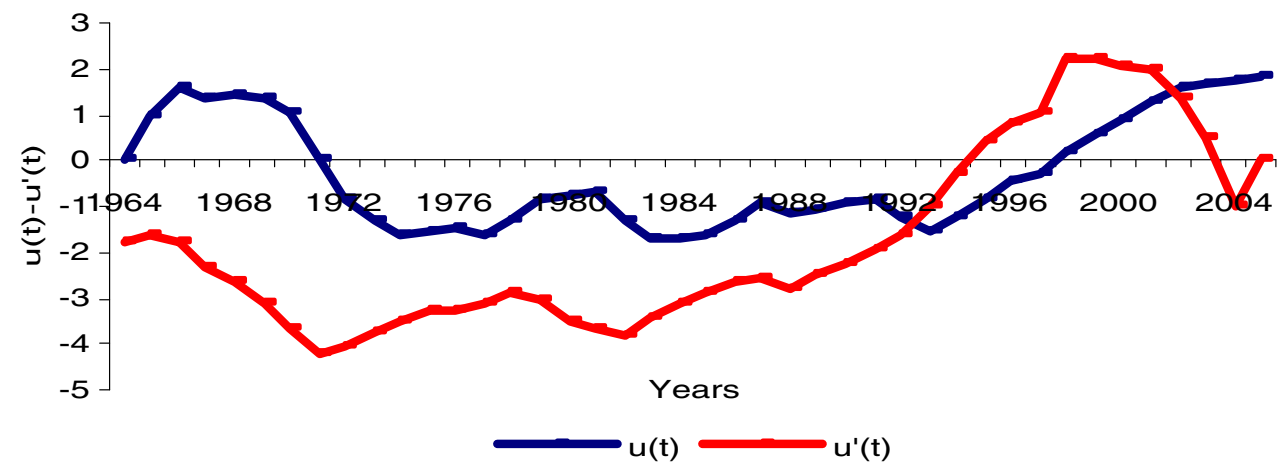

Urmia

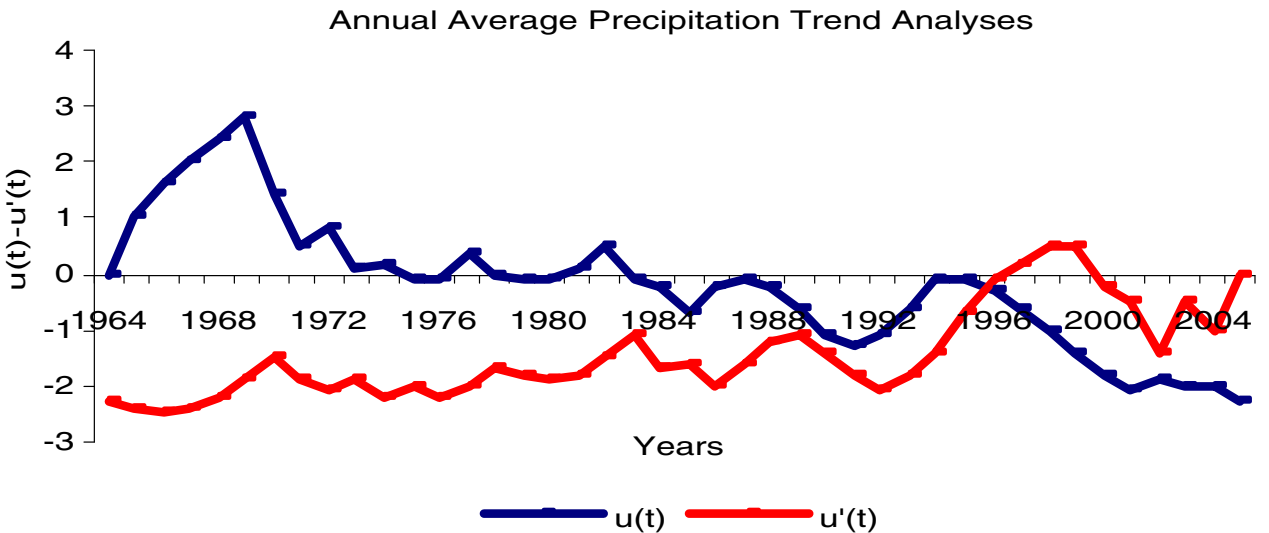

Fig. 6 Results of Mann-Kendall trend analysis for PDSI, annual mean temperature, and precipitation 


\section{Results}

The analysis of mean monthly PDSI for the period 19642005 in the Urmia station (Fig. 4) reveals a fairly curvilinear trend resulting from trends in precipitation and surface temperature with interannual variations from 1964 to 1996. During this period, on average, wet and drought episodes have hit the Urmia Lake Basin around every 5 years. The period between 1967-1969 and 1993-1994 are two prominent wet episodes and flooding where PDSI index reached +6.00 . Two single yeas of 1977 and 1982 were wet, however did not reach the above-mentioned level. Dry periods in the period 1964 to 1995 did not exceed -4.00 PDSI value. Nevertheless, since 1996, annual precipitation has sharply decreased and a different regime of interannual variations appeared. Our analysis showed that since 1996, moderate to extreme drought spells were mostly dominant in the Urmia lake basin, ranging between -2.00 and -6.00 . A reference to Urmia Lake altimetry recorded by TOPEX/Poseidon satellite (Fig. 3) shows that the height variations of the lake which was somehow stable around normal or slightly higher than normal levels started to decrease since 1997 in a linear trend. This complies with drought cycle which started since 1997 and reached extreme level from 2000 to 2001. Since then the lake has never recovered to reach normal levels.

Our analysis of mean monthly precipitation (Fig. 5) shows that the annual value of this parameter has decreased in a linear trend in all seasons during 1964-2005. However, noting that winter and spring are two major rainy/snowy seasons, a decrease of precipitation in these seasons leaves much more serious impacts on water reservoirs, the lake level, and runoff water in this basin. As regards to mean monthly temperature, our analysis revealed that although spring, summer, and autumn have not shown a sensible increase, mean temperature in winter (the months of January-February) has risen to above $0^{\circ} \mathrm{C}$.

The Mann-Kendall analysis reveals that from the mid1970s through 1980s, dry conditions persisted with less intensity and more frequency; however, since the late 1990s, drought episodes have become longer and more intense (Fig. 6). It also shows that there is a significant increasing trend in temperature, mainly starting since the beginning of the 1990s. Temperature analysis observed in the Urmia station indicates that an increase in the mean annual temperature $\left(0.014^{\circ} \mathrm{C}\right)$ has happened in cold seasons of the year; namely, winter, followed by spring $(0.05$ and $0.01^{\circ} \mathrm{C}$, respectively). There were no significant increasing trends in summer and autumn. The analysis has identified a statistically significant decreasing trend $(z=2.3)$ in precipitation observed in the Urmia station running almost in parallel with the temperature increase in the same period.

We have noted that seasonal droughts normally last from June to October, every year. This is an important period for the agriculture sector which imposes higher demand for water in the region (Fig. 7). The water deficit per months, from June to October, is considered the natural drought period and normal climatic nature of the Urmia Lake Basin. However, during dry periods when precipitation is lower than normal, particularly in autumn and winter, the water deficiency increases significantly. Table 4 indicates the parameters and their values which were used for calculation under Thornthwaite's method.

The number of rainy days recorded at the Urmia station shows that it can fluctuate to half ranging from 60 to
Fig. 7 Ombrothermic diagram of Urmia station by using Emberger method, and precipitation and potential evapotranspiration, Urmia station

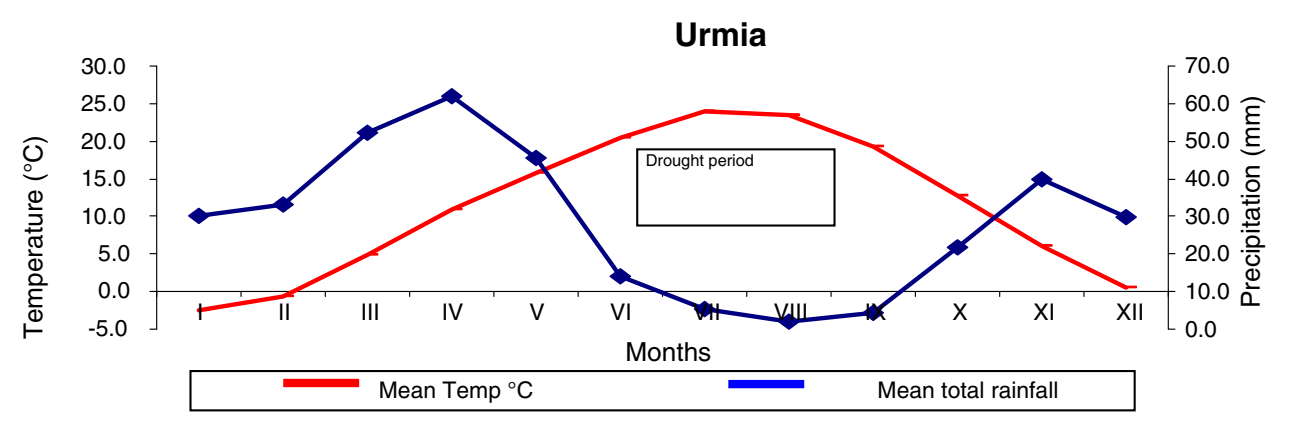

Urmia

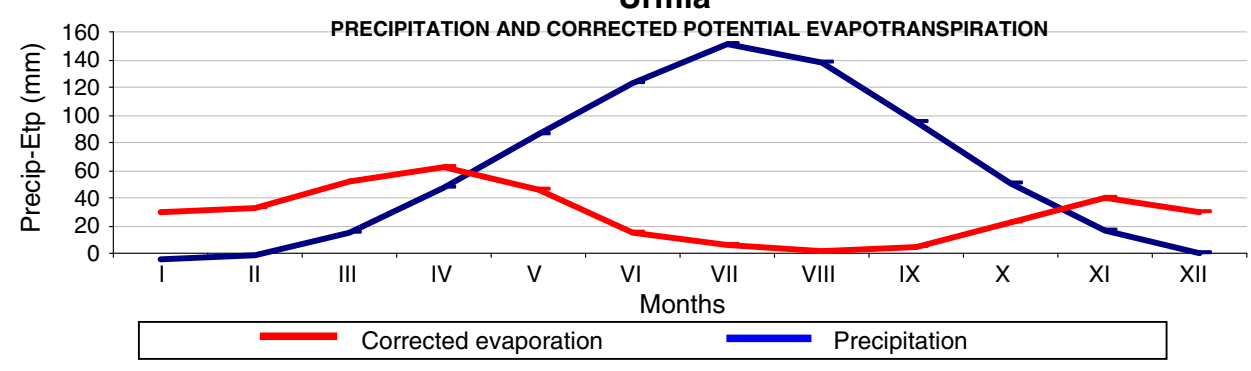


120 days, disregarding the amount of rainfall and its distribution over the year. With some exceptions in the early 1970 s and the 1990s, the number of snowy days has decreased in recent decade. Drought cycles in 2001 and 2005 coincide with fewer snowy days (Figs. 8 and 9).

The region shows obvious evidence of warming and increase in temperature combined with adverse effects of decreasing precipitation. Such a situation will lead to frequently occurring droughts as well as severe ecological and economical problems in the study area. Decreased land precipitation and increased temperatures that enhance evapotranspiration and drying are important factors that have contributed to this region experiencing droughts, as measured by the Palmer Drought Severity Index. The study showed that precipitation has mainly reduced in cold seasons in the study area. The decrease in winter amounted for $34 \%$, while in summer it was around $7 \%$ of the total annual value. It should, however, be noted that high increase in mean temperature followed by an increase in evaporation will negatively compensate far more a slight increase in precipitation.

We have also noted that the highest number of hot days in the study area is observed in the months of June to October. Hot days are defined as the days with maximum temperature more than $30^{\circ} \mathrm{C}$. Northwest of Iran for the period 1964 2005 has experienced a big reduction in the number of freezing days in winter in recent decade, comparing to the past. This is while the number of hot days $\left(>30^{\circ} \mathrm{C}\right)$ has increased in the same region. These changes comply with the Intergovernmental Panel on Climate Change (IPCC) Fourth Assessment Report which states the warming of the climate is consistent with observed increases in the number of daily warm extremes, reductions in the number of daily cold extremes, and reductions in the number of frost days at mid-latitudes (IPCC 2007).

\section{Discussion}

Drought is a recurrent climate phenomenon in Iran including in the Urmia Lake Basin, which leaves many socioeconomic and ecological impacts. We have noted an obvious evidence of marked increases in drought in recent decades which appeared more intense and lasted longer. The combined effect of decreased precipitation and increased temperatures enhanced evaporation in the region and led to dry conditions. Based on the PDSI analysis, very dry areas (defined as land areas with a PDSI of less than -3.0) have more than doubled in extent since the mid-1990s.

When the climate undergoes a warming and temperature shifts to a higher mean, without significant changes in the variability, it will bring fewer cold days, more hot days, and 
Fig. 8 Number of rainy and snowy days 1951-2005

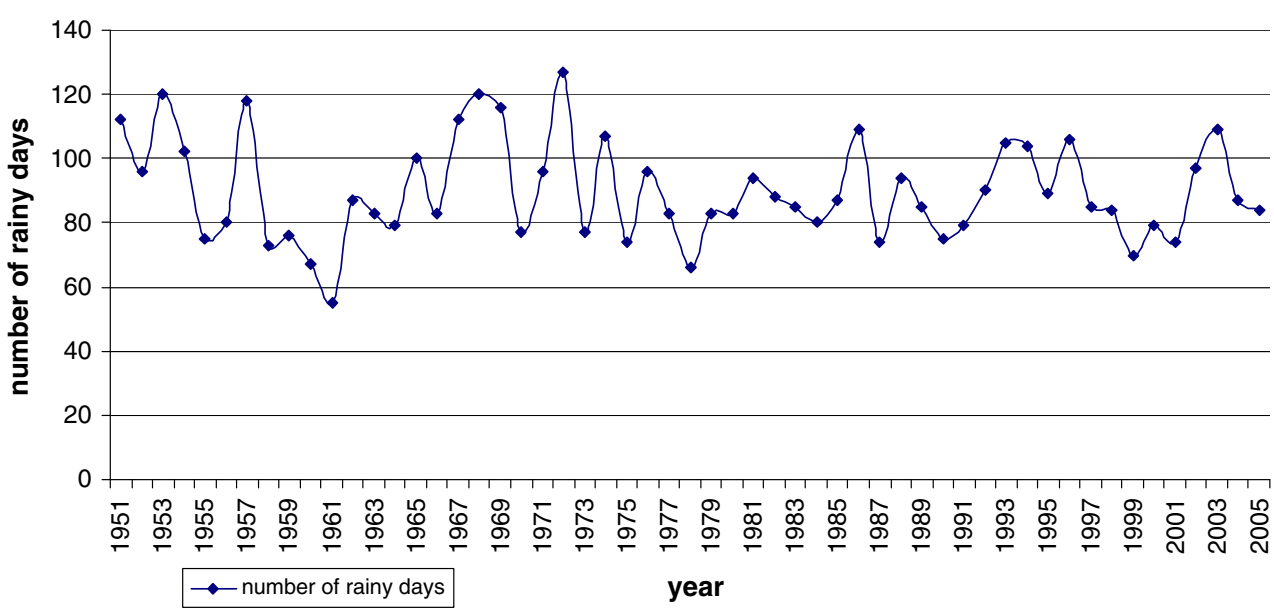

Urmia Station- NUMBER OF DAYS WITH SNOW

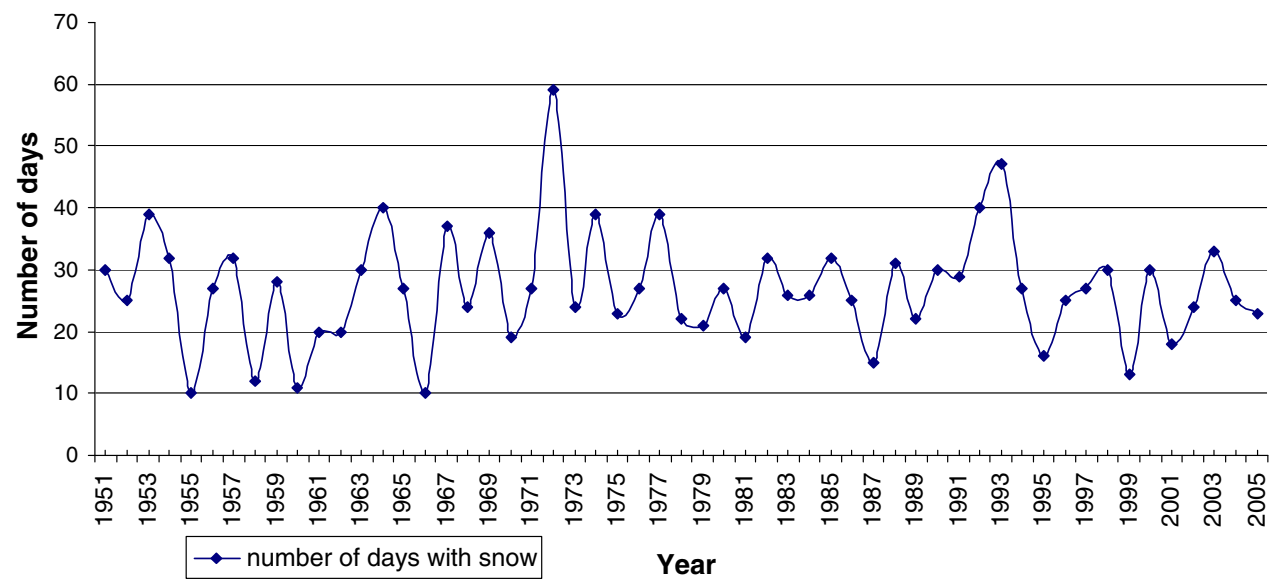

a higher probability that previous record-high temperatures will be exceeded. In the Urmia Lake Basin, a high reduction in the number of freezing days negatively affects agriculture and crop production. Persistence of such conditions leads to water stress, especially during the summer season, due to higher evaporation and insufficient accumulated rainfall from the preceding months.

Our results show that mean maximum and minimum temperatures, in the study area, during the 2001 and 2005 drought spells were higher than the values recorded for these parameters during the previous droughts in the 1970, 1975, and 1990. This suggests that potential evaporation has also enhanced as well. Record-high maximum temperatures have also accompanied the dry conditions in 2005. Although variations of precipitation averages over land are not very meaningful and may mask local variations, the PDSI suggests that there has likely been a large drying trend since the mid-1990s, particularly in cold seasons in the study area. Noting that the major part of precipitation in the Urmia Lake Basin falls in winter and spring and the highest seasonal decreasing rate in precipitation also occurs in these seasons, it is predicted that the runoff and groundwater resources will further come under pressure.

We noted that maximum record temperatures in summer can reach $39^{\circ} \mathrm{C}$ and number of hot days (temperatures higher than $30^{\circ} \mathrm{C}$ ) is dominant all through summer. This condition leads to excessive evaporative losses from reservoir surfaces. These catchments and their planned reservoirs play a very strategic role as they supply the urban water of Urmia city as well as irrigation for agriculture. This has left harmful impacts on soil moisture, agriculture, and water resources in the region.

Recent drought cycles in the Urmia Lake Basin have increasingly threatened the coastal regions as a result of receding lake level. Persistence of this trend will rapidly lead to the disappearance of the existing landscape, wildlife, as well as linking internal islands in the lake. Following these changes in the nature, secondary and social impacts of drought, such as increase in conflicts over water, higher rate of rural unemployment and reduction in agricultural productivity may stand as potential drivers for human displacements toward urban areas. 
Fig. 9 Mann-Kendall trend analysis of rainy days (1951-2005) and of snow cover (1961-2005)
TREND ANALYSIS OF NUMBER OF RAINY DAYS IN URMIA

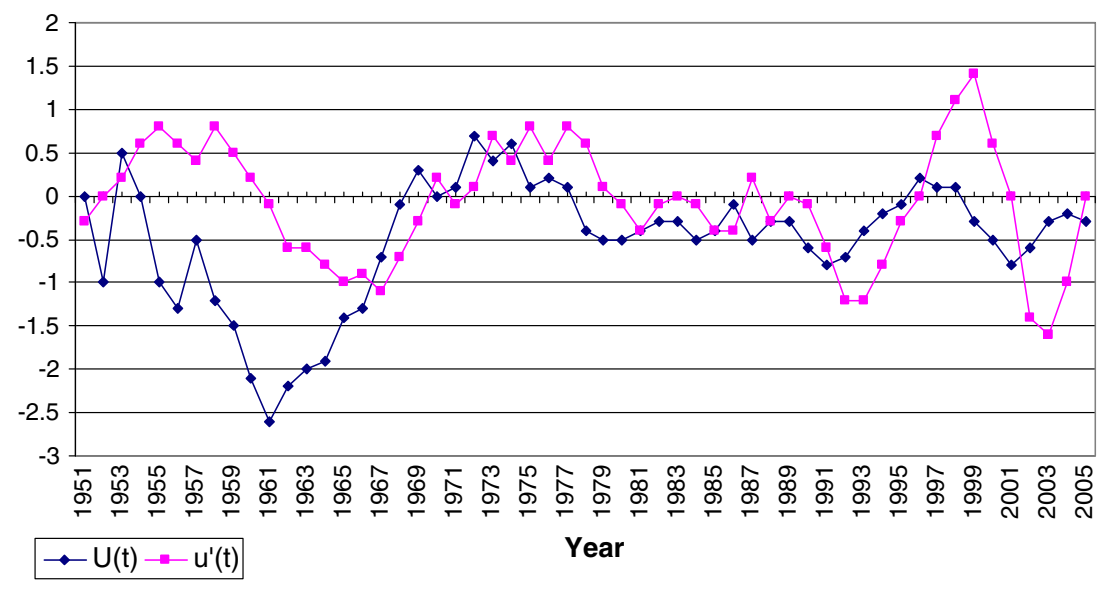

TREND ANALYSIS OF NUMBER OF SNOW COVER DAYS IN URMI A

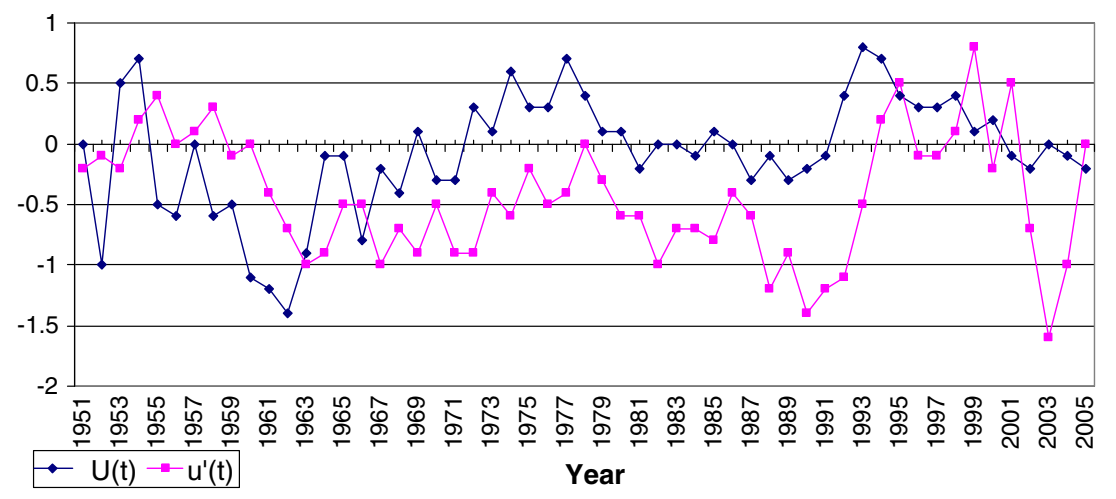

\section{Conclusion}

This study shows that the Urmia Lake Basin has experienced a rapid warming trend since 1996, particularly in winter. Major annual precipitation in water catchments of the basin happens during the winter and spring. Warming of these seasons has increased melting of snow and ice, further decreased water supply in summer, and reduced the reservoirs. On the other hand, higher temperature has led to higher evaporation and a larger gap in the water deficit. All above-mentioned trends are consistently associated with changes in a number of components of the hydrological cycle and systems such as widespread melting of snow and ice, increasing evaporation, and changes in soil moisture and runoff water. We assume that these natural processes are attributable to desiccation of the lake.

With regards to precipitation and evaporation, the Thornthwaite analysis shows that total precipitation minus evaporation $(P-E)$ from June to October is negative. This condition leaves major impacts on local agriculture and demand on ground water resources. Analysis of Palmer Drought Severity Index on observed data from the Urmia station suggests that drought onset has already become more frequent and intense in recent decades, leading to more rapid pace in desiccation of the lake, land degradation, and soil salinization. Such dramatic changes will ultimately trigger further degradation of the ecosystem leading to an impact on wildlife and human living standards in the region. It is most likely that the presence of a vast dried salt lake will significantly increase concentration of salt aerosols in the atmosphere and add to already existing indirect harmful impacts on the living condition both in rural and urban areas.

Our analysis has provided quantified values for the duration and intensity of droughts and visualized the water deficit in the selected area. Based on experience gained by drought spells in other parts of Iran, we assume that drought can stand as a potential driver for migration or human displacement, especially when water scarcity exceeds the local thresholds and meteorological drought turns into socioeconomic vulnerability and risk.

In order to better understand how climate change impacts will evolve in such a vulnerable area in the future and to build a bridge between drought as well as desiccation of the lake to forced human displacements, it is imperative to conduct an assessment of the socioeconomic consequences of climate change on the basis of the conclusions in the present paper. This will also help to explicitly trace the linkages between climate and environmental factors and develop conceptual models based on local physical and socioeconomic specifications such as loss of land, damage 
to agricultural products, reduced work opportunities, and reduced income which can contribute to migration and human displacement.

Acknowledgments The authors are grateful to I.R. of Iran Meteorological Organization for making data available for this study. We also express our thanks to Flurin Sutter for drawing the map of Fig. 1.

\section{References}

Aguilar E, Auer I, Brunet M, Peterson TC, Wieringa J (2003) Guidelines on climate metadata and homogenization. World Meteorological Organization, Geneva

Alley WM (1984) The Palmer Drought Severity Index: limitations and assumptions. J Clim Appl Meteorol 23:1100-1109

Azizi A (2000) An investigation to annual change of some chemical parameters include: active phosphor, phosphorous pesticides chlorophyll, and hardness, $\mathrm{Ca}, \mathrm{Mg}$ and $\mathrm{B}$ in soil, surface and underground water of Zarrineh roud delta. M.Sc. thesis, Urmia University, Chemistry Dept

Calvet C (1964) Le quotient pluviothermique de L. Emberger et l'évaporation. CR Soc Sci Nat Phys Maroc 30:55-61

Daget PLe (1977) Bioclimat méditerranéen: analyse des fromes climatiques par le systeme d'Emberger. Vegetation 34(2):87103

Dinpashoh Y, Fakheri-Fard A, Moghaddam M, Jahanbakhsh S, Mirnia M (2004) Selection 5 of variables for the purpose of regionalization of Iran's precipitation climate using multivariate methods. J Hydrol 297:109-123

Domrös M, Kaviani M, Schäfer D (1998) An analysis of regional and intra-annual precipitation variability over Iran using multivariate statistical methods. Theor Appl Climatol 61:151-159
Eimanifar A, Mohebbi F (2007) Urmia Lake (northwest Iran): a brief review. Iranian Artemia Research Center, Urmia

Emberger L (1930) La vegetation de la region méditerranéenne. Essai d'une classification des groupements vegetaux. Rev Botan 503:642-662, 504: 705-721

Ghaheri MH, Baghal-Vayjooee NJ (1999) Lake Urmia, Iran: a summary review. Int $\mathrm{J}$ Salt Lake Res Kluwer Acad Publ Neth 8:19-22

Ghasemi AR, Khalili D (2007) The effect of the North Sea-Caspian pattern (NCP), on winter temperatures in Iran. Springer, Berlin

IPCC (2007) Fourth Assessment Report (AR4), technical summary $\{3.2,3.8\}$. The physical science basis, WG I. IPCC, Geneva

Palmer WC (1965) Meteorological drought. Research paper no. 45. U.S. Weather Bureau, Washington, DC, p 58

PECAD (n.d.) USDA/FAS/OGA and NASA Global Agriculture Monitoring (GLAM) Project. Lake and reservoir surface height variations from the USDA's Global Reservoir and Lake (GRLM). http://www.pecad.fas.usda.gov/cropexplorer/global_reservoir/. Altimetric lake level time-series variations from the Topex/ Poseidon, Jason-1, Jason-2/OSTM, and Geosat Follow-On (GFO) missions

Rasuly AA (2005) Modelling of Urmia Lake coastal changes by applying an integrated RS/GIS approach, Tabriz University. GIS \& RS Center, Tabriz

Sneyers R (1990) On the statistical analysis of series of observations, WMO technical note no: 143. WMO, Geneva, pp 23-24

Sorgeloos P (1987) Brine shrimp Artemia in coastal saltworks: hydrobiological key to improved salt production and inexpensive source of food for vertically integrated aquaculture. Proc. International Meeting on "Saltworks Conversion for Aquaculture", Trapani, Italy, 9-11 May 1986, pp 133-141

Street-Perrott FA, Beran M, Ratcliffe R (1983) Variation in the global water budget. Reidel, Dordrecht, pp 331-345

World Meteorological Organization (2003) WMO-TD no. 1186, WCDMP no. 53. World Meteorological Organization, Geneva, p 55 